\title{
Quem são os "alunos chineses"? A necessidade de repensar a questão da identidade
}

Qiaorong Yan $^{1}$

Resumo: Este projeto tem o objetivo de repensar a questão da identidade associada ao aluno chinês em contexto de ensino de português como língua não materna. Expomos uma nova posição que o português vêm assumindo na China e as influências que tem promovido dentro do Império do Meio, entre a China e os países de língua portuguesa e nas interações entre chineses e estrangeiros construídas em português. Defendemos a necessidade de repensar conceitos de identidade numa perspectiva de um mundo mergulhado em superdiversidade.

Palavras-chave: interação intercultural; português como língua não materna; China; identidade.

Com a intensificação da cooperação econômico-comercial entre a China e os países de língua portuguesa, vê-se um grande aumento do número dos cursos de português nas universidades chinesas, de três no ano 2000 a dezessete no ano 2012. Do grande desenvolvimento do ensino de português como língua estrangeira, resultou a intensificação do intercâmbio acadêmico e da mobilidade dos docentes e alunos entre as instituições do ensino superior chinesas e estrangeiras. A maioria das universidades chinesas que possui curso de português adota o modelo de " $3+1$ " no seu programa de ensino, ou seja, os alunos estudam 3 anos numa universidade chinesa e um ano numa universidade brasileira ou portuguesa. Além de ter um ano de vivência num país de língua portuguesa, os alunos têm mais recursos e oportunidades do que nunca, para entrar em contato com a cultura da língua-alvo: ter professor brasileiro ou português nas universidades, ouvir rádio, ler jornais e assistir a programas televisivos em língua portuguesa na televisão, na internet, entrar em contato com a comunidade dos países/regiões de língua portuguesa, ou fazer amigos com as pessoas desses países/regiões pelas redes sociais da web, até fazer estágio numa empresa brasileira etc.

Numa era de globalização, com a evolução tecnológica, vivemos numa sociedade de superdiversidade (VERTOVEC, 2007). Como afirmam Blommaert e Backus (2011), num contexto de superdiversidade, um sujeito se

1 Professora e Coordenadora do Programa de Português da Universidade de Comunicação da
China, em Pequim. Doutoranda no Programa de Pós-Graduação do curso de Estudos Portugueses
da Faculdade de Ciências Sociais e Humanas da Universidade de Macau. E-mail:
silviadebj@yahoo.com.cn 
engaja numa ampla variedade dos grupos, redes e comunidades, e os seus recursos linguísticos são consequentemente aprendidos através duma ampla variedade de trajetórias, táticas e tecnologias, abrangendo da aprendizagem formal aos "encontros" informais com a língua. Neste novo contexto sociocultural, no qual se vê uma forte tendência à intenacionalização contínua do ensino superior e o aumento da mobilidade acadêmica, é importante para nós, docentes ou aprendizes de língua portuguesa, tanto falantes nativos como não nativos, termos uma visão mais aberta e não-essencialista sobre a língua, cultura e identidade.

Neste sentido, problematizamos as visões tomadas por alguns professores e académicos chineses e não-chineses que tratam os alunos chineses como membros duma coletividade homogeneizada. A passividade é uma palavra frequentemente utilizada para descrever como são esses alunos: receptores passivos de conhecimento, que adotam a memorização como principal estratégia de aprendizagem de uma língua estrangeira. Muitos estudos atribuem a passividade à "cultura chinesa", tentando explicar a performance dos alunos a partir do confucionismo ou do taoísmo.

Nessas perspectivas, a cultura é tratada como entidade homogênea e monolítica associada a lugares específicos (normalmente os países). Assumem ainda que existem essências culturais e que elas são influências primordiais na formação das caraterísticas de um indivíduo (não sujeitos), ou seja, defendem que as crenças e comportamentos são determinados pela filiação a um determinado grupo (normalmente nacional ou étnico). Estas perspetivas são consideradas essencialistas e tentam generalizar as caraterísticas dos alunos chineses, assim caem no risco de ignorar a complexidade e o dinamismo do ambiente cultural no qual se processam e reprocessam as identidades: um ambiente onde as realidades globais, nacionais, locais e individuais se interpõem, sobrepõem e interagem (GRIMSHAW, 2010, p. 245)

Um jovem chinês de uma cidade grande tem tantas influências de tantas línguas e culturas próximas e distantes que é uma limitação acreditar que esse é um sujeito previsível e constituído de uma forma essencialista a partir do confucianismo, taoísmo, budismo, comunismo e outros ismos.

Quanto ao ambiente cultural onde os alunos chineses vivem, não podemos negar a sua diversidade e o dinamismo a que nos referimos nem ignorar a sua influência na construção das identidades de um aprendiz chinês de língua portuguesa.

Em primeiro lugar, deve-se ter em consideração a influência das experiências de aprendizagem de língua portuguesa e o seu contato com a cultura de língua alvo na construção de identidades. Holliday et al (2004, p. 80) evidenciam a ligação entre as identidades e a aprendizagem de língua: 
The learning of a second or additional language, especially when it is 'forced' upon an individual by a (permanent) move to a new-languagespeaking community is a process which is inextricably linked to issues of culture and identity.

No processo de aprender uma língua adicional num novo contexto cultural, as identiades são reconstruídas e a história de vida é recontada (HOLLIDAY et al, 2004, p. 84). Neste sentido, entendemos que a identidade não é uma entidade fixa, é mutável e se reconstrói no processo de aprendizagem de uma língua adicional.

Em segundo lugar, é importante saber que a identidade é negociada e construída no discurso em interação (GOFFMAN, 1959; SOLLON e SCOLLON, 2001; HOLLIDAY et al, 2004; TEIXEIRA E SILVA, 2010). Em diferentes situações interacionais ou em diferentes momentos de interação, podemos projetar na linguagem diferentes facetas de quem somos.

Holliday et al (2004, p. 17-18) ilustram a projeção do "eu" no discurso como o uso de cartões identitários:

We are all, as individuals, members of a vast number of different cultural groups, and hence have a multiplicity of identities. [...] Although we are not fully in control of the resources that make up our identity, and we cannot choose our ethnicity, sex and so on, we can decide how to play the hand of cards that we have been dealt. We can work with the discourses available to us according to how we wish others to see us and how we wish to influence others' perceptions of the hand of cards we have been dealt.

É importante ressaltar que a identidade é negociada e co-definida pelos participantes na interação (GOFFMAN, 1959; 1980). Moita Lopes (2002; 2006), Hall (1997) e Vertovec (2010; 2007) têm trazido novas perspectivas para se pensar não em identidades, mas em pós-identidade uma vez que cada vez mais percemos que não somos homogêneos:

Essas percepções têm alterado como nunca a concepção homogénea da identidade social e têm levado a nos entendermos como heterogêneos e, ao mesmo tempo, fragmentados, e construídos em práticas discursivas situadas na história, na cultura e na instituição (MOITA LOPES, 2003, p. 15-16).

Por isso, para estudar a questão de identidade dos alunos chineses, torna-se fundamental ter em consideração o contexto da fala em interação.

Baseando-nos nas considerações acima referidas, propomos como agenda de estudos alguns temas ligados à questão de identidade dos aprendizes chineses de PLNM:

30 fragmentum, N. 35, parte II. Laboratório Corpus: UFSM, Out./ Dez. 2012 
- Como o processo de aprendizado da língua portuguesa, especialmente a experiência de estudar um ano no Brasil ou em Portugal, influencia a construção de identidade de aprendizes chineses de PLNM?

- Como as diferentes identidades sociais dos aprendizes são negociadas e co-construídas nas interações interculturais em contextos institucionais, como a sala de aula, e em contextos espontâneos?

Para concluir, queremos alertar para que os docentes de PLNM, sejam chineses, sejam estrangeiros, quando se referirem aos alunos chineses, não caiam no esterótipo essencialista e lembrem-se de que é no processo interactivo que nos constituímos como seres humanos no jogo social. E por isso acontecer em processo, não é possível definir/predizer/préconceber/rotular o outro.

\section{Referências}

BLOMMAERT, J.; BACKUS, A. Repertoires revisited: "knowing language" in superdiversity. Working Papers in Urban Language and Literacies, paper 67. At www.kcl.ac.uk/ldc, 2011.

GOFFMAN, E. Presentation of self in everyday life. New York: Anchor, 1959.

GOFFMAN, E. A elaboração da face: uma análise dos elementos rituais na interação social. In: FIGUEIRA, S.A. (org.). Psicanálise e Ciências Sociais. Rio de Janeiro: Francisco Alves, p. 76-114, 1980 [1967].

GRIMSHAW, Trevor. Styling the occidental other: interculturality in Chinese university performances. Language and Intercultural Communication, 10:3, 243-258, 2010.

HALL, Stuart. A identidade cultural na Pós-Modernidade. Rio de Janeiro: DP\&A, 1997.

HOLLIDAY, Adrian; HYDE, Martin; KULLMAN, John. Intercultural communication: Advanced resource book. London: Routledge, 2004.

MOITA LOPES, L. P. da. Identidades fragmentadas. Campinas: Mercado de Letras, 2002.

SCOLLON \& SCOLLON. Intercultural Communication: A Discourse Approach, Malden, MA: Blackwell Publishing, 2001[1995].

TEIXEIRA E SILVA, Roberval. A aula de língua não-materna sob uma perspectiva sociointeracional. In: Lima-Hernandes, Maria Célia \& Chulata, Katia de Abreu. Língua Portuguesa em foco: ensino-aprendizagem, pesquisa e tradução. Lecce: Pensa Multimedia Editores, 2010.

VERTOVEC, Steven. Towards post-multiculturalism? Changing 
Communities, Conditions and Contexts of Diversity. International Social Science Journal, vol. 61, issue 199. 2010.

VERTOVEC, Steven. Super-diversity and its implications. Ethnic and Racial Studies, 30: 6, 2007. 